\title{
The Mongolian Media Landscape in Transition
}

\author{
A Cultural Clash between \\ Global, National, Local and "no Nomads" Media
}

\author{
Munkhmandakh Myagmar \& Poul Erik Nielsen
}

\begin{abstract}
On the road from Bulgan to Sevrei, we noticed that almost all the gers that we passed in Sevrei had windmills, a satellite dish, and a vehicle. The soum itself seemed more developed than the other soums which we visited. There were 4 or 5 shops, a bakery and many other services. The soum had power from 7:30 - 12:00 PM. (The Gobi Initiative unpublished).
\end{abstract}

It is not my desire to destroy the original Mongolian identity but in order to survive we have to stop being nomads. Mongolian Prime Minister Nambaryn Enkhbayar (Murphy 2001)

Since the end of the communist era, Mongolian society has experienced dramatic changes towards a democratic society with a market economy. The country is in the midst of a challenging rebuilding of a new national identity while it undergoes two fundamental transition processes: one in the capital, Ulaanbaatar, and another in the vast rural areas. The two transition processes are interconnected and overlapping, yet quite different in scope.

Despite all the political, financial, and climatic hardship the country has endured during the past decade, the capital is on its way to becoming a complex modern urbanised city with significant reminiscences of the nomadic tradition and the

Monitoring Section, Press Institute of Mongolia, mandakh_m@yahoo.com

Department of Information and Media Studies, University of Aarhus,pnielsen@imv.au.dk communist era. The transition process in the countryside is towards a revitalisation of the traditional nomadic life and Buddhist religion, and simultaneously the rural areas, in respect to health and education, have witnessed significant deterioration in living standards.

This paper deals with the role of the media in these transition processes. Taking its point of departure in a brief presentation of the historical development of the Mongolian media during communism and the 1990s, the paper will document the major current trends in the Mongolian media landscape. The recently obtained freedom of expression has led to new booms in print and electronic media in the capital, Ulaanbaatar, while the media situation in the vast rural areas has deteriorated, and many aimags (provinces) have no local newspaper or local electronic media. In short, the media situation in Mongolia is characterised by great ambivalence.

The last part of the paper addresses, in a more exploratory discussion, some of the social and cultural implications of the current societal development and specifically looks at the role of the media in these transition processes.

\section{Brief History of the Mongolian Media}

Mongolia is a country covering a vast territory of 1.6 million square kilometres, but with a modest population of 2.4 million people. Traditionally the Mongolians lived as nomads, and traditional herding of livestock is still dominant in the rural areas, 
even though the government, during communism, forced many to work in collective farms. One fourth of the population is still living as nomads in gers (felt tents).

\begin{abstract}
But another crucial factor, especially since the 1960s, was urbanization. Throughout this century, but particularly its latter half when an ambitious industrialization programme gathered speed, Mongolia experienced an urbanization on an unparalleled scale and speed - from a few per cent living in towns in the 1920 s to 55-60 per cent in 1990. Since the demise of the command economy, however, there has been a marked abandonment of the towns as people move back full-time into the pastoral economy. [Gilberg and Svantesson 1996, p. 20]
\end{abstract}

The population of Ulaanbaatar has increased from 150,000 in 1960 to 800,000 today $^{1}$, thus the country is experiencing an ambivalent development, where more and more people move to the modern urbanised capital, while others turn to the traditional pastoral living.

Mongolia is divided into the capital and 21 aimags (provinces) each with around 50,000 to 120,000 inhabitants (Gobisumber aimag only 13,100). The Aimags are divided into 336 sums, which again are divided into around 1600 bags (brigades) with an average of 200 households. All levels have a local governor, and during communism the sum level was developed to include medical care, schools, libraries and cultural activities, and literacy was almost total. The communist government controlled the media closely. The national newspapers run by the state and party were well distributed to aimag centres, sum centres, and many times even out to bags. Besides the national newspapers, the aimag governments ran local newspapers and often radio and television stations as well. In addition were the state-run national radio and television covering almost all areas of the vast territory.

In the latter part of the $1980 \mathrm{~s}$, the government loosened its grip on the media partly due to the Mongolian version of 'Perestroika'. The editorial staffs were given more freedom to make independent decisions and journalists began to write about controversial issues, although still within the partyand government-controlled media. After the collapse of the Soviet Union in the late 1980s, a transformation of the authoritarian communication system took pace, and the birth of the free press was celebrated in February 1990 with the first issue of the newspaper Shine Toly (New Mirror). Within the next one and a half years, 155 new publications were launched, and the spectrum included a wide variety of newspapers with several run by political parties, some by independent political publishers, and a considerable number of 'yellow' tabloid newspapers.

The government hardly attempted to stop the enormous spreading of independent newspapers through direct sanctions ${ }^{2}$. The real restrictions came on the financial front, especially during an economic collapse in Mongolia in 1992 to 1994: The new independent newspapers were financially vulnerable, while the government media enjoyed considerable material and financial support from the State. The unequal market conditions threatened the new publications in practically all fields: In the supply of newsprint, printing and distribution. Newsprint became a scarce commodity because of suspension of supplies from Russia in 1993, and the rationing of newsprint, predictably, favoured government newspapers, since the primary publisher in Mongolia at that time was the state-owned Suhbaatar Publishing House, which published about $70 \%$ of Mongolia's printed material. Many of the independent newspapers appeared irregularly because of this shortage. The financial disadvantages forced private newspapers to charge higher prices compared to the government-owned papers, and the average income was so low that the majority of people could not afford to buy an independent newspaper. Consequently, many people had to rely on the information supplied by the relatively less expensive government newspapers. A new printing house, Free Press, founded in 1996 and funded by the Danish Development Agency, improved the situation of the independent print media outlets considerably. Nevertheless, the state-run daily newspapers Ardyn Erkh ${ }^{3}$ and Zasgiin Gazryn Medee dominated the print media market throughout the 1990s in terms of circulation.

The state-run Mongolian Radio was founded in 1934, and since 1960 the station has been broadcast nation-wide with an almost total coverage. In 1994, Mongolian Radio got a second channel Khukh Tenger broadcasting in Ulaanbaatar and the central region. In the mid-1990s, several private radio stations were launched in Ulaanbaatar besides a new station from the local government.

Mongolian Television was established in 1967, but it took a while before television played a significant role in Mongolia, since only 6 out of 100 households had a TV set in 1970, 14 out of 100 in 
1980, and 41 out of 100 in 1990. Until 1986, Mongolian Television only broadcast limited hours four nights a week.

Russian television has played a significant role in Mongolia, because a retransmission of the Russian station Orbit was launched as a second channel in 1970, and from 1976 Orbit could be received daily. Orbit broadcast more hours than Mongolian Television, and Orbit enjoyed great popularity, especially among youth, until it ceased in the beginning of the 1990s.

In the mid-1990s, two private television stations were launched in Ulaanbaatar. A Christian American-Mongolian foundation, $A M O N G$, established Eagle TV in 1994, and the biggest Media Corporation in Mongolia, Mongol News Co., launched MN Channel 25 in 1995. In 1999, the local government in Ulaanbaatar launched $U B S T V$.

In the mid-1990s, several cable-TV systems were established in the many huge apartment complexes in Ulaanbaatar and in a few of the urban centres in the countryside. With the introduction of cable and to a lesser degree satellite-TV, some Mongolians acquired access to a wide range of transnational and Asiatic television channels.

During communism, the rural areas had good access to the widely distributed national print media as well as to radio and television for those households with radio and TV receivers. Furthermore, all aimags had a government-run local newspaper that was distributed to all sums and many bags. Many of the aimag centres had a local radio and/or TV station too, and some of them also took the opportunity to cut away from the Mongolian Radio transmission for four half-hours a week for local programmes (Simering 99). This well-organised, top-to-bottom dissemination of information from the different government levels broke down after the collapse of communism. The national print media are no longer distributed to the same extent, and many of the local media outlets have closed, so national radio and television play a more significant role.

\section{The Media Law of 1998}

The Mongolian constitution adopted in 1992 guaranteed the freedom of expression as well as the right to seek and receive information, but it took 6 years before these freedoms were specified in a media law. The media law is a serious step forward in respect to media freedom. The censorship authority was abolished already in 1989 , but it was not until the 1998 media law that censorship was prohibited.

One of the main issues in the 1998 media law was to free all state-owned media from government control. The Parliament Standing Committee on the State Institution was entrusted to elaborate a draft decision regarding the property, structure, composition and statutes of the institutions.

The former state-run and -owned newspapers Ardyn Erkh (now Udriin Sonin) and Zasgiin Gazryn Medee (now Zuuny Medee) were privatised in 1999 according to the law, although the way it happened created some criticism among journalists and media people. According to the law, Mongolian Radio and Mongolian Television were to be dismantled and organised as national public broadcasting institutions, but this has not yet happened. Neither has the national news agency Montsame been transformed into a public entity.

\section{The Current Media Landscape}

In 1999, the Press Institute of Mongolia sat up a Danida-funded monitoring project that has established systematic and thorough documentation of the Mongolian media landscape in regard to supply and structure ${ }^{4}$. The following interpretation of the Mongolian media situation is based on annual reports of 1999 and 2000. Unfortunately there has not been systematic monitoring in respect to readership and radio and television audiences ${ }^{5}$, and neither is it possible to get reliable figures on penetration of radio and television sets and the access to cable TV.

In 2000, a total of 111 newspapers, 24 magazines and $6 \mathrm{TV}$ and radio stations have been registered as new entities by the Ministry of Justice and Interior, bringing the total number of registered outlets since 1990 to more than 1270. Many of these registered outlets are no longer running and some might not have been launched at all or only published one or two issues.

According to the monitoring project, 160 newspapers (5 daily, 6 biweekly, 28 weekly, 54 bimonthly, 37 monthly and 33 irregularly) and 37 magazines were published in 2000, 28 radio and 29 television stations were broadcasting, 8 cable TVsystems were operating. The Mongolian media landscape is blooming with a quite impressive number of media outlets for a country of 2.4 million people, and new media outlets are mushrooming. Concerning freedom of expression, it is not only formal rights to freedom of expression and the 
prohibition of censorship that have been established in Mongolia, but many Mongolians are taking real advantage of freedom of expression.

In a way, the Mongolian media landscape might be seen as volatile, with so many new outlets launched every year and just as many closed, and the media landscape is definitely going through some dramatic changes. On the other hand, some of the major trends are fairly stable both within the press and the electronic media.

\section{Newspapers and Magazines}

The number of daily newspapers has remained unchanged since 1999. The total circulation of the 5 daily newspapers decreased from 45,000 in 1999 to around 41,000 in 2000. Udriin Sonin ${ }^{6}$ (the former state-run Ardyn Erkh) is by far the largest with a circulation of 17,700 in 2000 , decreased from 22.300 in 1999 and far below the circulation of Ardyn Erkh during communism. The other former state-run newspaper, Zuuny Medee, and the privately established newspaper, Unoodor, ${ }^{7}$ come in second and third with a circulation around 7-8,000. A quite impressive proportion of $90 \%$ of daily newspapers are sold via subscription.

Besides the circulation of 41,000 daily newspapers, there is a significant circulation of weekly newspapers of around 120,000. The privately established Seruuleg ${ }^{8}$ is by far the largest with 37,100 , and the likewise privately established Khongorzul comes in second with 17,600.

In any case, the total circulation of newspapers is relatively low compared to the great variety in supply, and the total circulation indicates that many people, even in the capital, are not reading newspapers regularly. A decisive reason for the relatively low total circulation of newspapers might be the price. The average price for daily newspapers rose in 2000 from 200 to 250 tugrek (US\$ 0.25). Compared to an average monthly salary around 40,00060,000 tugrek, it is quite expensive to buy a newspaper every day.

Magazines play a minor role in Mongolia. In 2000 , there was only one weekly magazine with a circulation of 3,000 and 11 monthly magazines with a total circulation of 5,100 .

\section{Radio and Television}

Mongolian Radio is the only radio station broadcasting nation-wide. The station is financed by three sources: state subsidies, license fees, and advertisement, and the station broadcasts an exten- sive and varied programming (in 1999: news 17\%, politics/social $20 \%$, music $16 \%$, education/youth $9 \%$, culture $5 \%$, advertisement $12 \%$, etc.).

Mongolian Radio also broadcasts a local channel in Ulaanbaatar, Khukh Tenger, likewise with a varied programming, but broadcasting 54\% music and entertainment. Besides the two channels from Mongolian Radio, there are 6 radio stations broadcasting in Ulaanbaatar. The local government runs the station Ulaanbaatar Radio, which mainly plays music $(72 \%)$, and there are 5 private commercial stations also dominated by music and entertainment, some of which have news and politics as well.

In many ways, the television situation corresponds to the radio situation. Mongolian Television is financed in the same way, and it broadcasts a varied programming, nation-wide and 7 hours a day (in 2000: news 20\%, movies and dramatic TV series $20 \%$, education and youth $15 \%$, politics/social $10 \%$, advertisement $8 \%$, etc.). Seventy-five percent of the programming is nationally produced.

In Ulaanbaatar there are 4 local television stations: $U B S T V$ run by the local government, Eagle $T V$ run by Among, and two private commercial stations MN Channel 25 and Noyan (only in some parts of Ulaanbaatar). UBS TV and MN Channel 25 have a varied programming with news, politics/social, and a great deal of movies. Around half the programmes are nationally produced. Eagle $T V$ is predominantly broadcasting news (69\%) and Christian family-value programmes. Besides a daily nationally produced news programme, the main part of the news programming on Eagle TV is taken from CNN (partly delayed and dubbed, partly directly from $\mathrm{CNN}$ ).

Besides the terrestrial television there are 8 cable TV-systems operating in Ulaanbaatar and in a few of the urbanised areas in the countryside. The cable systems are providing between 14 and 33 channels of predominately foreign television. There are channels from Russia, China (Inner Mongolia and China in general), Korea and Japan as well as transnational channels such as Star TV, CNN, BBC, and Deutche Welle. There are no available data on the penetration of cable.

\section{Local Media}

While the media landscape in the capital might be seen as blooming, the situation in the countryside is discouraging. Here, the former system of staterun media has fallen apart, and no new sustainable alternative has been established instead. 
By the end of 2000, 24 newspapers were published in the countryside. Of these 4 were weekly, 17 bimonthly, 4 monthly, and 5 published irregularly. 12 newspapers were recently established and 16 newspapers ceased during 2000, among those several of the recently established. Several aimags had more than one newspaper, while 7 out of the 21 aimags had no newspaper by the end of 2000 . The average circulation of the local newspapers was 800 , and the total annual circulation for all the local newspapers was 406,000 to a countryside population of 1.6 million.

The countryside population has access to some of the newspapers from Ulaanbaatar. The 5 daily newspapers and about one third of all the newspapers are distributed nationally to the aimag centres, but the newspapers are rarely distributed to the sums as the state- and party-run newspapers were during communism. There is no exact data on how many copies are sold outside Ulaanbaatar. Hence it is difficult to tell how great an impact the varied supply of national newspapers has in the countryside, but it is obvious that the access to printed information is very limited outside the aimag centres?

The most influential media in the countryside are the state-run radio and television stations, which have almost total coverage. The fact that the signal is accessible in all rural areas does not mean that all households have access to radio and television. Most of the nomad families do have a radio, while television sets are rarely seen among the herders, and even though the preamble tells of nomads having access to satellite television, this is not common.

13 out of the 21 aimags had a local radio station. Half of the radio stations broadcast regularly and extensively for 3 to 16 hours daily, and in the urbanised areas in Darkhan-Uul and Orkhon aimags, there are three competing radio stations. The rest of the radio stations broadcast irregularly for only 1 to 7 hours each week.

17 aimags have a local television station, but it is only in Darkhan-Uul and Selenge aimags that the stations are broadcasting extensively, while all others are broadcasting between 30 minutes and 7 hours each week. Most of the local radio and television stations can only be picked up in a limited range around the aimag centre.

The 66 local media outlets employed about 215 people full time, making $12 \%$ of the total number of employees media employees. The average number of employees per local newspaper was 2.5 , while it was 3.2 for radio stations and 4.0 for television stations. These figures include directors, editors, journalists, technical support, and administration.

Almost half of the local newspapers have no editorial office, and they are in general very poorly equipped regarding phones, computers, and Internet access. Only a few of the local newspapers have access to local printing facilities, so $70 \%$ of the local newspapers are sent to Ulaanbaatar for printing at the Free Press printing house and then sent back again. This takes at least 2-3 days, so the local newspapers cannot compete in terms of time and news value.

The electronic media are also working under very poor conditions. The government-run local television station in Uvurkhangai can illustrate this. The station broadcasts 90 minutes each week. The programmes are produced live on tape in a provisional studio at the town hall with one camera. Afterwards the tape is brought to the transmitter on a nearby hilltop.

Some local radio stations have been set up with donor money and hence from the beginning better equipped and staffed, but the stations cannot sustain that level without continuous donor support.

\section{Financial and Legal Aspects}

When the monitoring project was established, one of the aims was to monitor financial matters as well, because it is important that the media outlets operate within a sound financial environment, otherwise they cannot serve their purpose in the democratic process. Many of the media outlets refrained from participating in this part of the monitoring, so the project only has valid data on the ownership of the media.

As mentioned earlier, the two former state-run national newspapers have been privatised, so on a national level the state is not running any newspapers. In the countryside, the local governments are still running some newspapers, but from 1999 to 2000 newspapers owned by state organisations have decreased from 15 to $11 \%$. Sixty-five percent of the newspapers are privately owned, while NGOs and political parties own the remainder. Hence it is obvious that, on a national level, Mongolia has developed freedom of expression that is widely accessible. It is more questionable, however, whether the print media is operating in a sound financial environment. There is no doubt that some of the daily newspapers as well as some of the most popular weeklies are profitable. But the many closed-down outlets indicate that it is extremely difficult to break even, and many of the 
small newspapers are philanthropic and political projects.

As regards electronic media, the situation is quite different. Because of the scarcity of frequencies, there is a long international tradition that freedom of expression is in some ways suspended in the electronic field, since a broadcaster needs a license. The main problem in the current Mongolian situation is that the state is running monopolies within national radio and television. This is reminiscent of the communist era and in direct conflict with the 1998 media law demanding that the government should give up control of media institutions.

The state-run monopolies are a serious problem, because radio and television are very influential media both in the capital and in the countryside. The situation in Ulaanbaatar is quite complex because the local government is running both a radio and a television station. On the other hand, there are competing private stations in Ulaanbaatar, and this mixed broadcasting system has already forced the government-run stations to adjust their programming policies. In any case, the government control of national radio and television is hampering the process of transforming Mongolia into a completely democratic society with free and independent media. One positive approach would be to transform the state-run radio and television stations into public broadcasting companies out of reach of the government.

The idea of public broadcasting in Mongolia is not new. In 1991 came the first proposal for a public broadcasting channel that should supplement the state-run channel. Since then the concept of turning the state-run stations into public broadcasting has been discussed extensively, but the different parties in power have not been ready to give up control over the national broadcasting media.

In the countryside, the problem of governmentowned media is in some ways even worse, because in many cases the local media have a total monopoly on local issues. Furthermore, the financial situation for local media is so bad that it is impossible to run local media of a certain quality without financial support. The most urbanised areas, such as Darkhan and Erdenet, are exceptions. The local governments could allocate money for the local public broadcasters and/or independent community newspapers, but this is unlikely to happen in a situation where health care and education are deteriorating.

Donor organisations like UNESCO and MFOS (the SOROS Foundation) do support a few radio stations and a few newspapers. Most donor organisations see radio as the most appropriate medium for local communication. In 1998, MFOS proposed a three-year programme with the following goals:

- Set up an effective regional information network to strengthen local voices.

- To increase the quality and quantity of local programming.

- To increase herder oriented central programming.

- To increase the professional skills and knowledge of rural broadcasters.

To advance these goals, we propose the creation of a rural radio service with the following structure:

Establish a station in each aimag that has the ability to originate daily local information programming of substance. (Siemering 99)

The proposal can be seen as ideal, because it stresses the participatory aspect in local media projects and at the same time focuses on the need for enhancing professional skills. MFOS never started this comprehensive project, but they did start local radio stations in Darkhan and Selenge, two of the largest urban centres in the countryside, and the signals can be picked up in a narrow range (10-15 kilometres) of the aimag centre. The real challenge, though, for a local network of radio stations would be in the rural areas, and so far most rural areas are not even close to having access to local radio.

\section{Journalistic Standards}

Above we have analysed the transition in respect to supply and structure, but the media is also changing in terms of content. One of the main difficulties is to establish genuine professional journalistic standards. For decades journalists have worked within a system controlled by the government, and it is not easy for them to break out of the mould. It is extremely difficult for critical journalists to get access to information from the authorities and other relevant sources, and the sources of information expect the same level of loyalty from journalists as they experienced during communism. Furthermore, the Mongolian Radio, Mongolian Television, and many of the local media outlets are still run by the government, so many journalists are working within a system of double standards.

It will take some years before a transformation of journalistic standards is accomplished, and this 
will involve more training of the journalists, some structural changes of the electronic media as well as a change of attitude on all levels. On the other hand, Mongolia has, at least in the capital, taken a huge step toward a thriving media landscape to the benefit of the democratic process and as an invaluable source in the daily life of modern Mongolians.

\section{Issues to be Addressed}

After this factual interpretation of the historical development and the current media situation, we would like in a more exploratory discussion to address some of the social and cultural implications of the current societal development in Mongolia. Specifically we would like to discuss some issues related to the role of the media in the country's rebuilding of a new national identity. Finally, we would like briefly to discuss some specific problems concerning the development of the local media in Mongolia.

When dealing with the societal development in countries in transition, it is important to analyse the issues in a contextual perspective and to avoid a general and often Western-dominated theoretical perspective. The Mongolian development is in many ways unique, because of the nomadic heritage, the seven decades of communist rule, the long oppression of Buddhist religion, the geo-political position between Russia and China, and the geography of the country.

In Ulaanbaatar you easily see the complexity of the society. Young people in fashionable clothing and with mobile phones are living side by side with young Buddhist monks and people of all ages wearing traditional clothing adapted to the Mongolian climate. Busy shopping streets and markets are situated beside the Soviet-style apartment buildings and large neighbourhoods with gers and livestock. Ulaanbaatar is a modern urbanised city with significant reminiscences from the nomadic tradition, or as Prime Minister Enkhbayar put it: "This is a half-nomadic city" (Murphy 2001).

The rural areas are also undergoing significant changes. Even though the communist rule made major political mistakes, such as forced collectivisation of nomads and the oppression of the Buddhist religion, the centralised development during communism did succeed in establishing a widespread health care and education system for the whole population, including the nomadic herders. This system was supported by thorough dissemination of information and systematically organised political and cultural activities even in remote rural areas. In rural areas, the collapse of communism led both to a relaxation of the restrictions and to a disintegration of the centrally supported social system. In subsequent years, it has not been possible for the changing governments to re-establish a well-organised social system. Many aimags today lack sufficient health workers and medicine, and schools and libraries do not have access to new books, so teaching in the primary schools is often based on old books from the communist era.

During the past two years, harsh living conditions in the rural areas have made matters worse because of extremely cold winters and dry summers. The consequence has been a large-scale migration to the capital and other urbanised areas, but there has also been substantial traffic in the opposite direction, with people migrating back to the nomadic life as a refuge from the dreary 'modern' life.

Hence, Mongolian society is facing not only financial and social problems, but the country must also establish a new identity for the Mongolians. This new complex identity must bridge the huge gap in living conditions and life expectations between modern urban and traditional rural areas, between youth and old people in urban as well as rural areas, and between growing social differences.

The euphoria over obtained democratic freedom has long been replaced by a severe hangover and a more down-to-earth understanding of the social and political realities. On the other hand, Mongolia has many strong integrative elements such as ethnic homogeneity, strong family ties, as well as mythic, religious, and social rituals like the family celebration Tsargan Sar and the sportive Naadam festival.

\footnotetext{
Through apparatuses as diverse as museums and village dispensaries, post offices and police stations, tollbooths and telephone booths, the nation-state creates a vast network of formal and informal techniques for the nationalization of all space considered to be under its sovereign authority. States vary, of course, in their ability to penetrate the nooks and crannies of everyday life. Appadurai p. 189.
}

In the midst of these two contradictory but intertwined transition processes, the Mongolian society is rebuilding the national identity on the remains of the communist system and the still vital traditional family and religious traditions. This process is foremost dependent on social, economic, and political development and it will take place through negotiation between modernity and traditional values, be- 
tween the state and social classes, and between the local (neighbourhoods), the national and the global level. The process is fragile and the Mongolian State is far from being able 'to penetrate the nooks and crannies of daily life'.

Among other things, literature, art, folk and popular culture and the media contribute to the development and negotiation of the local and national identities. In the following we address the role of the media in this complex development.

\section{Media and Democracy}

Since the start of the first independent newspaper, Shine Toly, in 1990, Mongolia has witnessed an impressive utilisation of freedom of expression. In the past decade, new print and electronic media have been launched continuously, and although many media outlets have ceased to exist, the number of operating media in the capital is significant.

Founded on political freedom and freedom of expression, the impressive and varied supply of partisan political newspapers serves the political debate in the public sphere and has been essential to the democratisation process in the country. Furthermore, the varied supply of newspapers insures against any democratic setbacks, although the political situation is continuously volatile. Although the supply of newspapers might be varied, the total circulation is not impressive and indicates that only a limited part of the population is engaged in the democratic process.

The political newspapers are often one-sided, focusing on political issues and they are less interested in more soft issues related to the social and cultural changes in the daily lives of the Mongolian people. There are several yellow newspapers focusing on crime, violence and sex, and although they cater to specific needs among the readers, they do not provide valuable contributions to a better understanding of the new complex Mongolian society. This might be one of the reasons why the newspapers have quite a low total circulation and hence only a limited social and cultural impact outside a narrow political discourse.

The political newspapers, Eagle TV, the staterun Mongolian Radio and Mongolian Television, and the majority of local media have, despite all their differences, one thing in common: they are all governed by a strong sender-oriented desire to agitate. This mode of address is characteristic of a dominance model (Servaes, 1996) where the media communicate in a paternalistic manner, seeing the receivers as passive subjects who need to be enlightened or educated.

\begin{abstract}
Nomadism puts the group ahead of the individual: "Social cooperation whether voluntary or legally enforced is the keystone of both nomadic and socialist-communist societies." [Area Handbook for Mongolia, p. 180] Political loyalty to a patron or leader in traditional Mongolian society was smoothly transferable to the communist era's authoritarian relationships. Concepts such as popular sovereignty, political freedom and majority rule never had a place in Mongolia in the past.
\end{abstract}

The challenge for Mongolia today, in the era of democratization, will be to break this psychological mindset to encourage personal initiative and civic responsibility. (Campi 1996, p. 93).

It might be correct that, in order to survive, the nomads are raised within a collective mindset, and there might be some resemblance between the nomadic and communistic authoritarian relationships and this paternalistic mode of address. The political elite acts in this manner, since the shifting governments, irrespective of political views, strained to maintain government control over national radio and television.

On the other hand, it has often been argued that the Mongolians have an individualistic mindset. They are sceptical to accepting authoritarian rules, and they enjoy freedom to an extent that does not conform to modern industrialised societies. The silent resistance to the communistic rule, the revival of the Buddhist religion, and the varied supply of newspapers representing competing views suggest that there is at least a competing individualistic mindset.

Anyhow the varied newspaper supply and the launch of commercial radio and television stations point to the fact that the Mongolian media landscape in its totality, at least in the capital, is changing in the direction of a pluralistic model. The Mongolians have accepted the democratic challenge.

\section{Media and Cultural Identity}

As previously mentioned, there are unfortunately no reliable figures on readership and radio and television audiences. Mongolian Television has recently established a weekly audience survey in Ulaanbaatar of the station's own programmes. The 
ratings are unbelievably high, but the surveys still suggest that television in general, and Mongolian Television in particular, is playing a significant role in the daily lives of people living in Ulaanbaatar. It is not possible to support this with additional facts, but the general opinion among professional media people in Mongolia is that radio and television play a significant role in the capital.

It is worth mentioning that Mongolian Television, and to some degree MN Channel 25 and UBS $T V$, provides varied programming of predominantly nationally produced programmes within news, politics, documentaries, youth/education, and dramatic TV-series. Audience surveys conducted by Mongolian Television suggest that the national programming is among the most popular, and that the foreign programmes only play a marginal role. There is probably no doubt that nationally produced radio and television are some of the main forces in establishing a new social and cultural identity for the Mongolian population living in the capital.

Eagle $T V$ is a specific case. The station is, on the one hand, an example of the utilisation of freedom of expression and the right to hold different religious opinions. On the other hand, the station is in two ways representative of globalisation. First, following a thousand-year-old tradition of religious globalisation, this electronic 'missionary man' is agitating for Christianity through old American family-values programmes. Second, the station is supporting the modern globalisation of Westerndominated news flow and world order through the retransmission of CNN programming, either delayed and dubbed or live retransmission of the CNN signal. The two different forms of globalisation converge since the latter is a tool for Eagle TV to proselytise the Mongolian Buddhists through the lure of Western capitalism and the American suburban lifestyle. As far as we can assess, Eagle TV as such has had limited penetration, but the many different lures of consumerism and Western lifestyle are nevertheless making an impact on modern life in Ulaanbaatar, so it is hard to isolate the impact of Eagle TV.

To thoroughly understand the character of the media's role, it would be necessary to include textual analyses of the different media, but this is not available in Mongolia and it is beyond the scope of this paper. Instead, we would like to raise a few issues to be addressed in further research. In a situation where societal development encompasses two fundamental transition processes, it is interesting to analyse how the media deals with the tension between the two processes. Since 1) all the signifi- cant media are based in Ulaanbaatar, 2) most of the media are aimed at the population in Ulaanbaatar, and 3) $88 \%$ of all media employees are working in Ulaanbaatar, it seems reasonable to assume that the media are more concerned with the transition process in the capital than with that in the rural areas. If this is the case, the media will support a new "national' identity marked by the limited yet complex local experiences of the tension between modernisation and traditional values in daily life in the capital.

\section{Local Media}

In the factual presentation of the current media situation in Mongolia, we pointed out that the media situation in the rural areas is paradoxical, because the lack of local media means that people in the countryside have limited access to local media while they have better access to national media and sometimes even international media. The two most important media in the rural areas are the government-run Mongolian Radio and Mongolian Television, the latter depending on people's access to electricity and a television set. As previously mentioned, we have no access to data on the rural population's use of national programming, nor to data on how satisfied audiences are with such programming.

In any case, it is obvious that there is a huge gap between the specific needs for local information and the information provided by the national media. The rural people using the accessible national and international media are constantly confronted with the difference between the presentation of the modern urban life and their own pastoral way of living. The increased migration to the capital indicates that rural people are tempted by the urban life as an alternative. This might partly be caused by the luring presentation of urban life in the media, but there are many other reasons for migration, not least the lack of prospects in the rural areas in general and the harsh winters the past two years. The media certainly play a secondary role, and it is by no means problematic that rural people have access to the content of modern media, instead it is problematic that they do not have access to local media.

Fortunately, we know a little about the rural people's interest in local media from two surveys conducted by two donor organisations in relation to the implementation of donor-supported local radio stations (MFOS) and local newspapers (Gobi Initiative). Both surveys suggest that the rural popula- 
tion is very interested in receiving information on local issues. The herders main interest is in access to reliable information related to their own lives, e.g., prices on the market for cashmere, rice, etc., news about relatives in other sums and aimags, and more detailed local weather forecasts. The rural people are interested in local media, but the few existing local media have only to a limited extent been able to connect to that interest, partly because the local media have had difficulties in providing relevant information to the rural people.

The main problem for the local media is nevertheless related to the infrastructure and the financial situation. It is impossible by reasonable means to establish and run local media in the rural areas, so it is hard to see how the local media situation can be improved unless the financial problems are solved politically or by substantial donor funding.

At present, the Mongolian government is developing a radical political strategy for the rural areas involving dramatic change for the herders. The goal is to urbanise up to $90 \%$ of the Mongolian population over the next 30 years.

Under the ambitious social-engineering project, a series of regional cities connected by modern communications would be built along a 2,400kilometre east-west highway [the Millennium Road], transforming a country where almost half the people live in rural areas and some $40 \%$ of the entire population rely for their livelihood on tens of millions of livestock. ...

Agriculture, now largely tens of thousands of medium sized herds, would shift to intensive, well-managed animal husbandry involving as little as $10 \%$ of the population. (Murphy 2001).

In other words, rural people must abstain from being nomads and move into urbanised centres in the countryside. This is a radical and centralist approach to the geographical problems of the country. To some extent the plan is understandable in terms of the difficulties of developing and sustaining an infrastructure within health care, education, etc. Furthermore, the devastating living conditions in the rural areas the past two winters are definitely reasons for innovative initiatives. But the plan is a dramatic transformation process changing the lives of hundreds of thousands of people.

Campi argues that many of the economic advisers to Mongolia have been trapped in a misapprehension of the universal excellence of modern freemarket economic theories.
The fundamental significance of nomadism to Mongolia's future growth is ignored today by some of these advisers, because they believe that integration of the country's extensive pastoral nomadic economy with its thin dispersion of people into an intensive concentrated agricultural economy mixed with industry is inevitable. (Campi, 1996 p.92)

The present government has obviously accepted the ideas of the foreign advisers, and it seems that the government is ready to give up the traditional nomadic culture for a modernisation of the country.

The phenomenon of nomadism is an alternate,
living economic culture with its own laws and
social relations that must be further studied and
understood, if true economic reform and mod-
ernization are to be successfully implemented
in Mongolia. (op. cit. p.93)

It is, of course, a political question to what degree a country wants to develop the rural areas in respect to health care, education, media and infrastructure in general. The media situation will obviously reflect these political decisions, but it is difficult to see how a dramatic transformation process can be successful unless the involved people participate in the process.

\section{Mongolia - A Unique Case}

Above we have addressed some cultural and social issues concerning the media's role in the current transition of Mongolian society. We have put together bits and pieces to shed some light on the issues, and we have pointed out interesting facts and relations, which again have raised new important questions. On the other hand, we have by no means been able to analyse all the issues satisfactorily, because we lack detailed knowledge on the media content and on readership and audiences.

On the national level (in the capital), Mongolian media have quite successfully served the public sphere in the democratisation process, but the media situation in general is in many ways out of synchronisation with the current social and cultural changes. Especially the dominating paternalistic mode of address is an inadequate way of addressing the complex societal changes, although this mode of address is in some ways well known from both the nomadic tradition and the communist era.

The media situation is in a complex transition process, where the media themselves are undergo- 
ing structural, financial, and editorial changes and simultaneously forced to operate in a society in the midst of complex transition processes. The Mongolian situation is in many ways unique and it does not fit into any well-established general theory, thus analyses must address its specificity.

The national media and the local media in the capital have merged both on the sender and the receiver end. All the 'national' media are based in the capital and 9 out of 10 media employees are working there. The 'national' media are also aimed at the population in the capital (the government-run national electronic media is partly an exception). This capital/national level is predominant even in terms of content, such that the local and global levels play minor roles.

The local media are in their insignificance extremely local, and the media outlets are continuously struggling to survive. The global level is primarily represented by an electronic 'missionary man', while the global influence on the national media is limited. In the cable TV systems there is a second kind of globalisation, or maybe more correctly, a kind of trans-national regionalisation with Inner-Mongolian (Chinese), Russian, Chinese and Japanese TV, but the impact of trans-national cable TV seems to be limited.

Mongolian media are Mongolian.

\section{Notes}

1. Unofficially the population in the capital is about a million, and in the outskirts of the city, several suburbs have grown up, where migrants are living in traditional gers.

2. Since autumn of 1991, all new media outlets should be registered at the Ministry of Justice; however, this procedure has been of a formal nature.

3. According to Williams (1996) Ardyn Erkh had a circulation of 162,000 in 1990 .

4. The main goal of this monitoring project has been to establish reliable documentation on the development of the Mongolian Media Landscape. The systematic information retrieval has been based on declarations from the publishers, and although the project has not been able to directly verify the data, cross-checking of some of the data has shown that the retrieved information is reliable.

5. Every week Mongolian Television conducts a small survey of their own programmes on audiences in Ulaanbaatar.

6. Udriin Sonin is partly owned by the only very large private media company Mongol News Corporation. The company owns the newspapers Udriin Sonin (partly), Unuduur, Tavan Tsagarig, Bi Bi Bi, Weekend Nyam, and UB Post, the radio station FM 107.5, and the television station MN Channel 25

7. Unoodor is owned by The Mongol News Company, which owns several weekly newspapers and the television station MN Channel 25 as well.

8. Seruuleg also runs a private radio station in Ulaanbaatar in addition to a minor second newspaper.

9. A new UNESCO-financed study Mongolia: Access to books and other printed Materials shows that the public's access to information in the rural areas has decreased during the past 10 years.

\section{References}

Appadurai, Arjun (1996) Modernity at Large. Cultural Dimensions of Globalisation. Public Worlds, vol 1. Minneapolis: University of Minnesota Press.

Bruun, Ole \& Odgaard, Ole (ed.) (1996) Mongolia in Transition. Old Patterns, New Challenges. Richmond: Curzon.

Campi, Alicia J. (1996) Nomadic Cultural Values and Their Influence on Modernization In: Ole Bruun \& Ole Odgaard (ed.) (1996) Mongolia in Transition. Old Patterns, New Challenges. Richmond: Curzon.

Gilberg, Rolf \& Svantesson, Jan-Olof (1999) The Mongols, Their Land and History. In: Ole Bruun \& Ole Odgaard (ed.) Mongolia in Transition Old Patterns, New Challenges. Richmond: Curzon.

The Gobi Initiative (unpublished).

Media Freedom in Mongolia (1996) International Federation of Journalists.

Monitoring Mongolian Media 1999 (2000) Press Institute of Mongolia.

Monitoring Mongolian Media 2000 (2001) Press Institute of Mongolia.

Murphey, David (2001) No Rooms for Nomads. Far Eastern Economic Review, May 31, www.feer.com/ _0105_31/p030region

Servaes, Jan (1999) Communication for Development. Cresskill, N.J.: Hampton Press.

Servaes, Jan, Jacobsen, Thomas L. \& White, Shirley A. (ed.) (1996) Participatory for Social Change. London: Sage.

Siemering, Bill (1999) Rural Radio in Mongolia (unpublished).

Williams, John W. (1996) Mass Media in Post. Revolution Mongolia (unpublished). 